March 14, 2005

U. S. Department of Energy

Idaho Operations Office (NE-ID)

1955 Fremont Avenue

Idaho Falls, ID 83401-1235

Subject: Transmittal of Deliverable

Reference: Grant No. DE-FG07-03RL14520

GA Project 30171

Per the requirements of the above reference Grant, enclosed herewith is one copy of the document listed below.

Report No. $\quad \underline{\text { Title }}$

GA-C25006 High Efficiency Hydrogen Production From Nuclear

$(03 / 05)$

Energy: Laboratory Demonstration of S-I Water-

Splitting (Project 2002-001-F)

For Period March 2005

I

Please direct all technical questions regarding the enclosed to Ben Russ at telephone (858) 455-3902. All contractual questions are to be directed to the undersigned at telephone (858) 455-3057, facsimile (858) 455-3545 or via E-mail at ramona.goulette@gat.com.

Sincerely,

Ramona Goulette

Contract Administrator

Enclosure: As Noted 


\title{
High Efficiency Hydrogen Production From Nuclear Energy: Laboratory Demonstration of S-I Water-Splitting (Project 2002-001-F)
}

HI Decomposition for the Sulfur Iodine Cycle using Reactive Distillation

by

\section{Bob Buckingham General Atomics}

\author{
Prepared under \\ International Nuclear Energy Research Initiative \\ (INERI) Program \\ for the U.S. Department of Energy
}

MARCH 2005 


\section{Introduction}

The governments of the United States and France have undertaken a joint laboratory demonstration of the Sulfur-Iodine cycle for hydrogen production. The participating institutions are between Sandia National Laboratories-Albuquerque (Sandia), Commissariat à l'Energie Atomique (CEA) and General Atomics (GA). This report documents the efforts of General Atomics. Sandia National Laboratories, the lead laboratory, provides overall project reporting and documentation.

The S-I cycle consists of three sections integrated to produce hydrogen from water in a multi-step process. In Section I, the Bunsen reaction, sulfur dioxide $\left(\mathrm{SO}_{2}\right)$ and iodine $\left(\mathrm{I}_{2}\right)$ are reacted with water to produce sulfuric acid and hydriodic acid (HI). CEA has taken responsibility to demonstrate the Bunsen reaction in a stand-alone experiment. SNL is working with Section II, where the sulfuric acid is decomposed to regenerate $\mathrm{SO}_{2}$. GA's role has been to demonstrate Section III, the decomposition of HI to hydrogen and iodine, on a laboratory scale.

The reactive distillation of $\mathrm{HI}$ to hydrogen and iodine on a lab-scale has not been attempted before. The $\mathrm{HI}-\mathrm{I}_{2}-\mathrm{H}_{2} \mathrm{O}\left(\mathrm{HI}_{\mathrm{x}}\right)$ solution is extremely corrosive, and boils at temperatures approaching $300^{\circ} \mathrm{C}$. Operating pressures under these conditions are in the range of 20 to 50 bar. Glass was chosen as a suitable material for handling the corrosive properties of the solution, but this requires measures to operate at these high pressures. One way to do this is to place the distillation column inside a pressure vessel, and match the pressure outside the column to the pressure within. Thus, a large part of the experimental effort is directed toward the containment and control of this differential pressure system.

In addition, the small diameter and close tray spacing of a laboratory-scale column makes adiabatic operation an issue. To minimize heat losses and to prevent a thermal "short circuit" of the column, the pressure vessel is internally insulated. Figure 1 illustrates the concept of the distillation column within a pressure vessel. Figure 2 is a photograph of the pressure vessel installed in the laboratory. Figure 3 describes the glass column used in the experiments.

\section{Current Project Status}

\section{Differential Pressure Control Scheme}

The differential pressure control scheme has been modified based on results from trials using water. Previously, pressure within the glass column was generated by vaporizing liquid in the column. This pressure was measured by a transducer and compared to the nitrogen pressure in the pressure vessel. The pressure controller adjusted nitrogen pressure to match the pressure within the glass column.

With the new design, a nitrogen purge gas is used to pressurize the glass column before heat is applied. Rather than a capillary tube, a needle valve is used to regulate the gas flow from the column. These changes allow for increased flexibility in operating conditions, and it is a more robust method for bringing the system up to the desired 
pressure. The new design for pressure control has been successfully tested, including with HI solution.
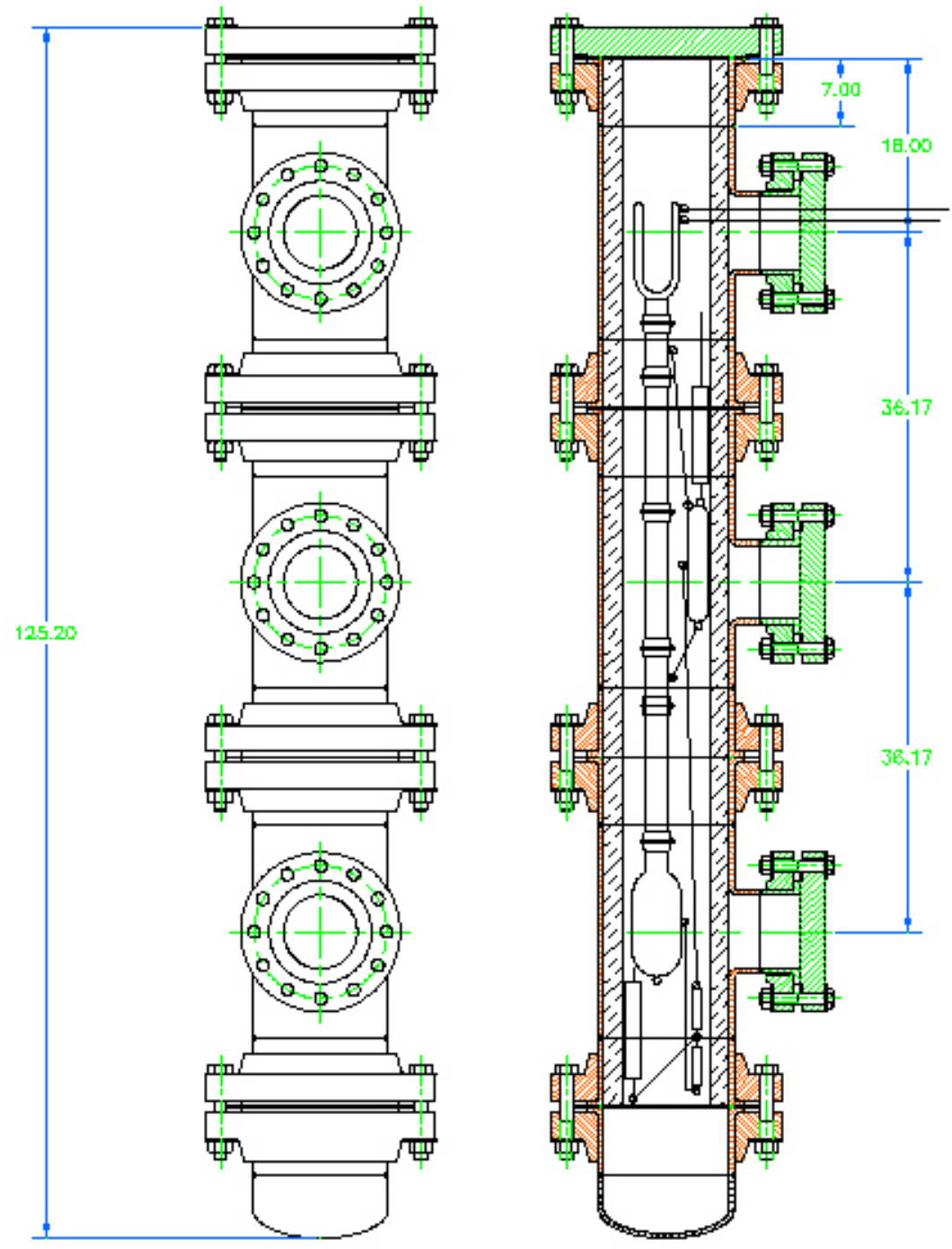

CUSTOM 7 " STUBS

$$
14 \text { " SCH 80-600\# }
$$

Figure 1. Placement of glass distillation column within pressure vessel. 


\section{LabVIEW-Based Control System}

Process control is done through the use of a LabVIEW software interface. A single screen contains controls for the differential pressure system, the column temperature controls, and the controls for pumps (when used) for fluid transfer during operation.

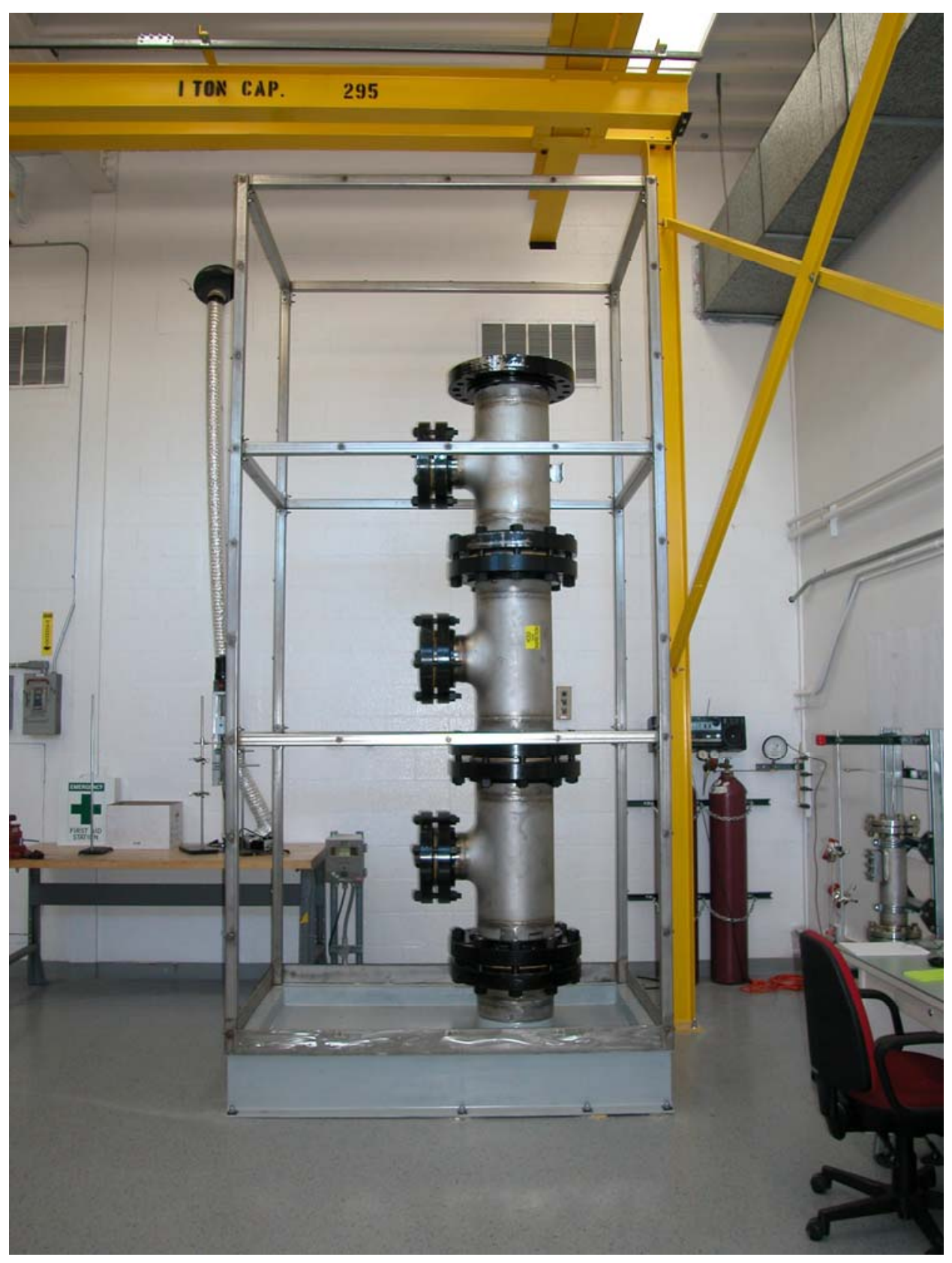

Figure 2. Pressure Vessel for Containment of Reactive Distillation Experiment. 
Trials have shown that the LabVIEW-based control system works satisfactorily. After trials were conducted with water, modifications were made to allow for more continuous boiling in the column reboiler.

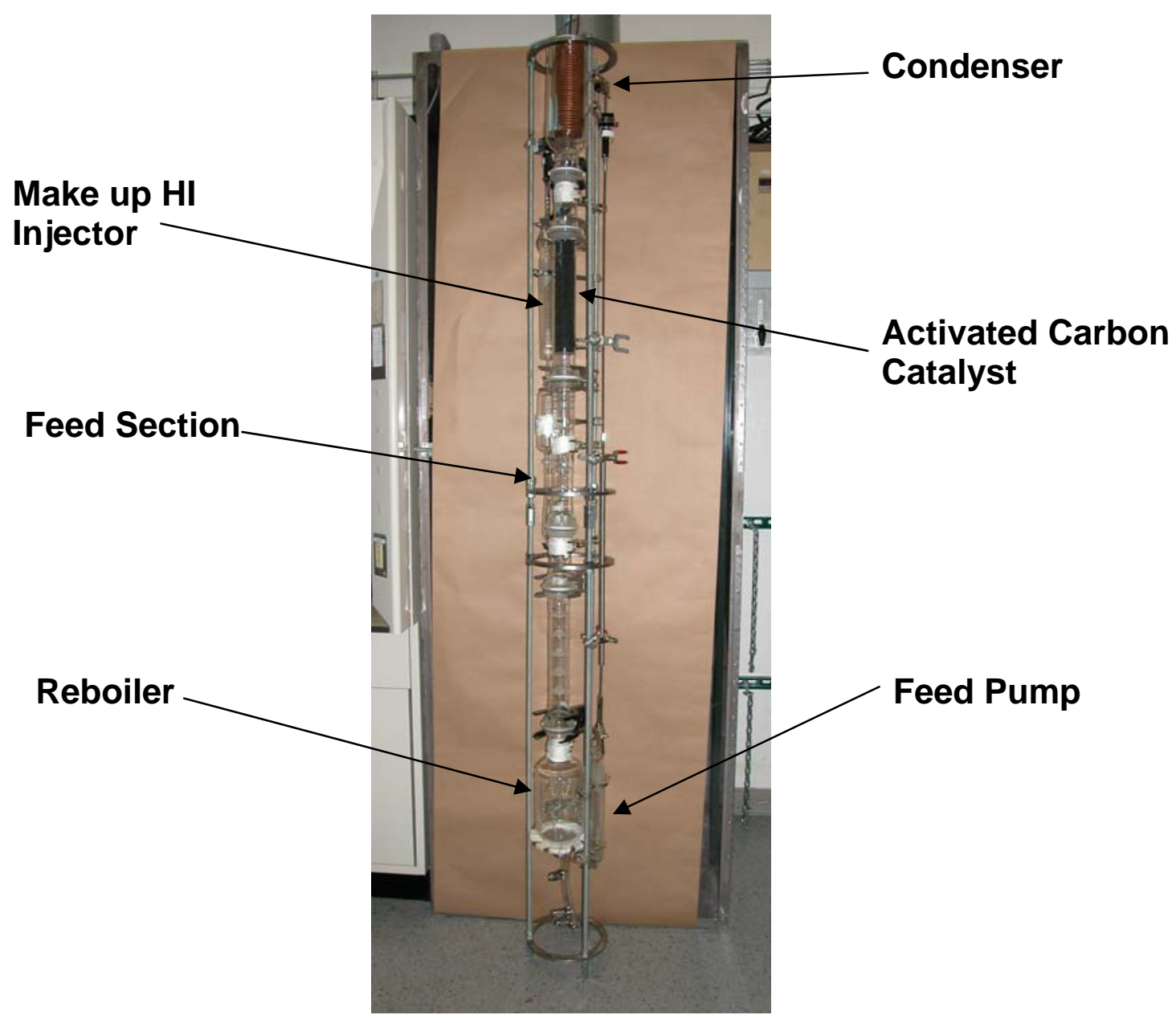

Figure 3. Reactive Distillation Column

The battery power supply for the pressure controller and pressure transducers has eliminated the electrical noise problems seen previously. The LabVIEW software and the nitrogen pressure controller show no evidence of electrical interference using battery power.

\section{Initial Experimental Trials}

Initially, the entire apparatus was assembled and run using water to test systems and tune the process control devices. While the overall concept was shown to be valid, issues with the equipment caused delays. Trials with water showed that modifications to the internal glass plumbing were required before HI could be introduced. The differential pressure 
system underwent modifications. The previously mentioned difficulties with electrical noise were noted and overcome.

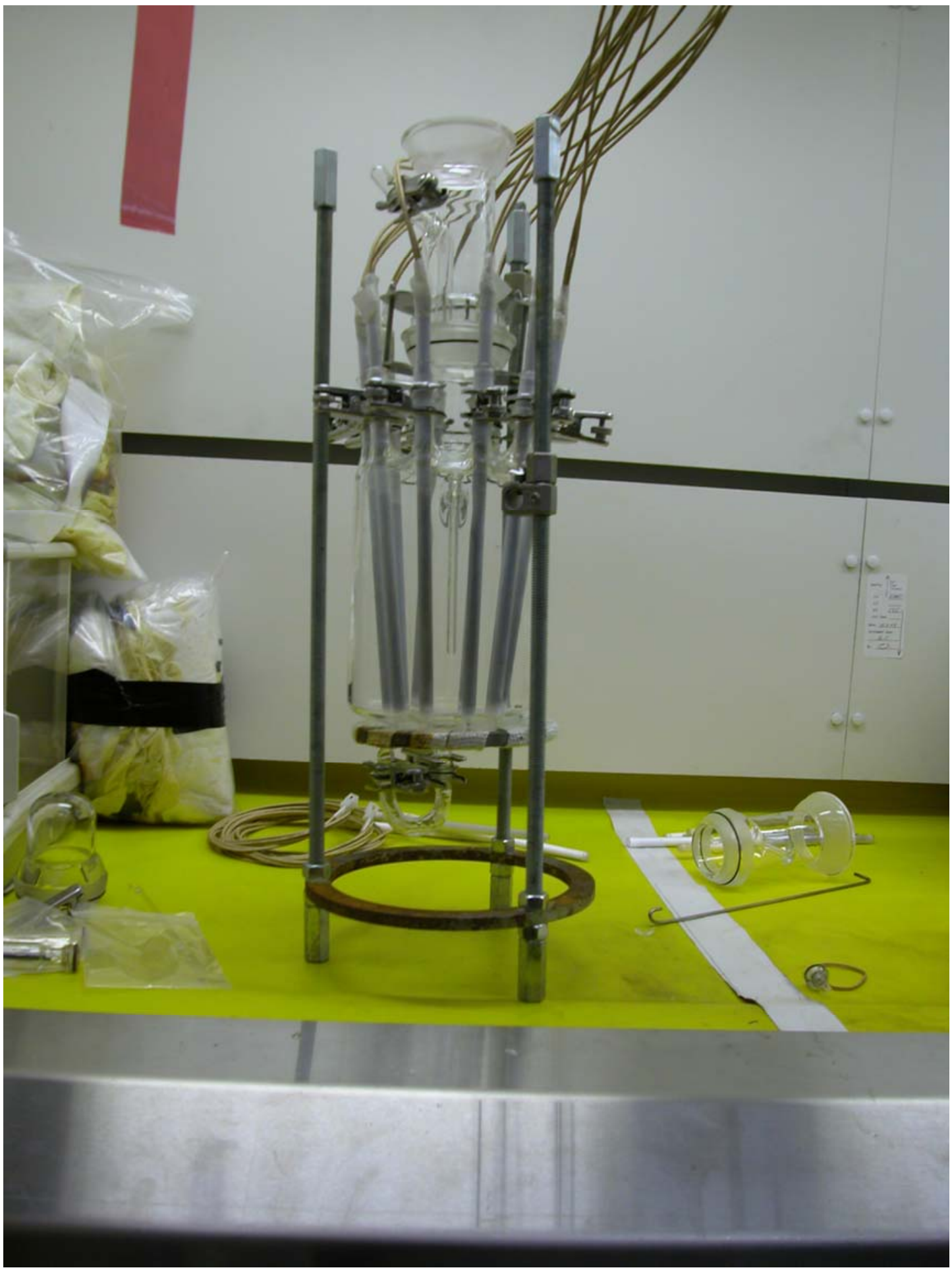

Figure 4. Glass column reboiler with quartz immersion heaters installed. 
After these issues were resolved, trials with $\mathrm{HI}$ solution were begun. Figure 4 shows the column reboiler with detail on the quartz immersion heaters and the thermowell, and Figure 5 shows the reboiler charged with HI solution just before installation into the pressure vessel.

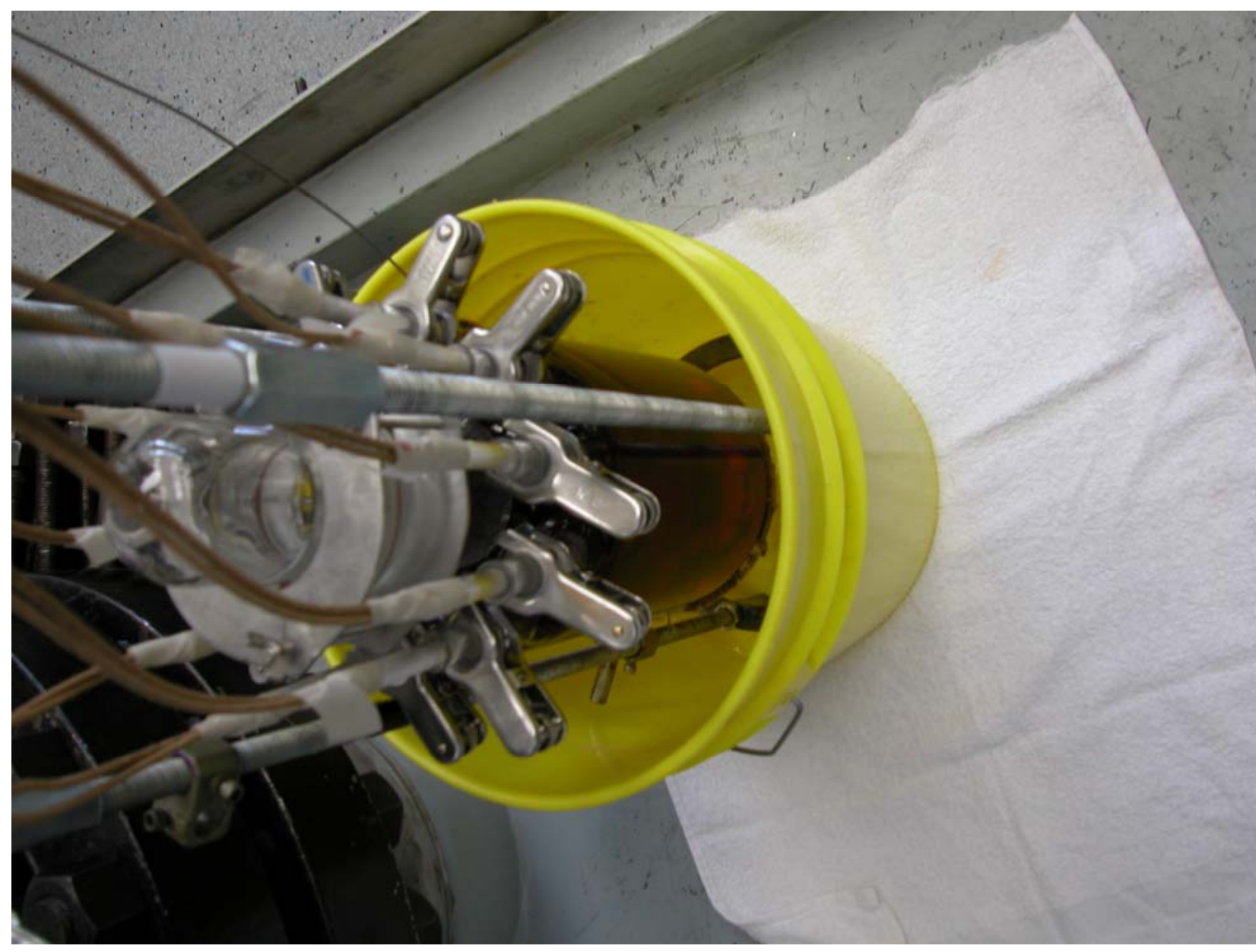

Figure 6. Glass column reboiler charged with HI solution ready for installation into pressure vessel 


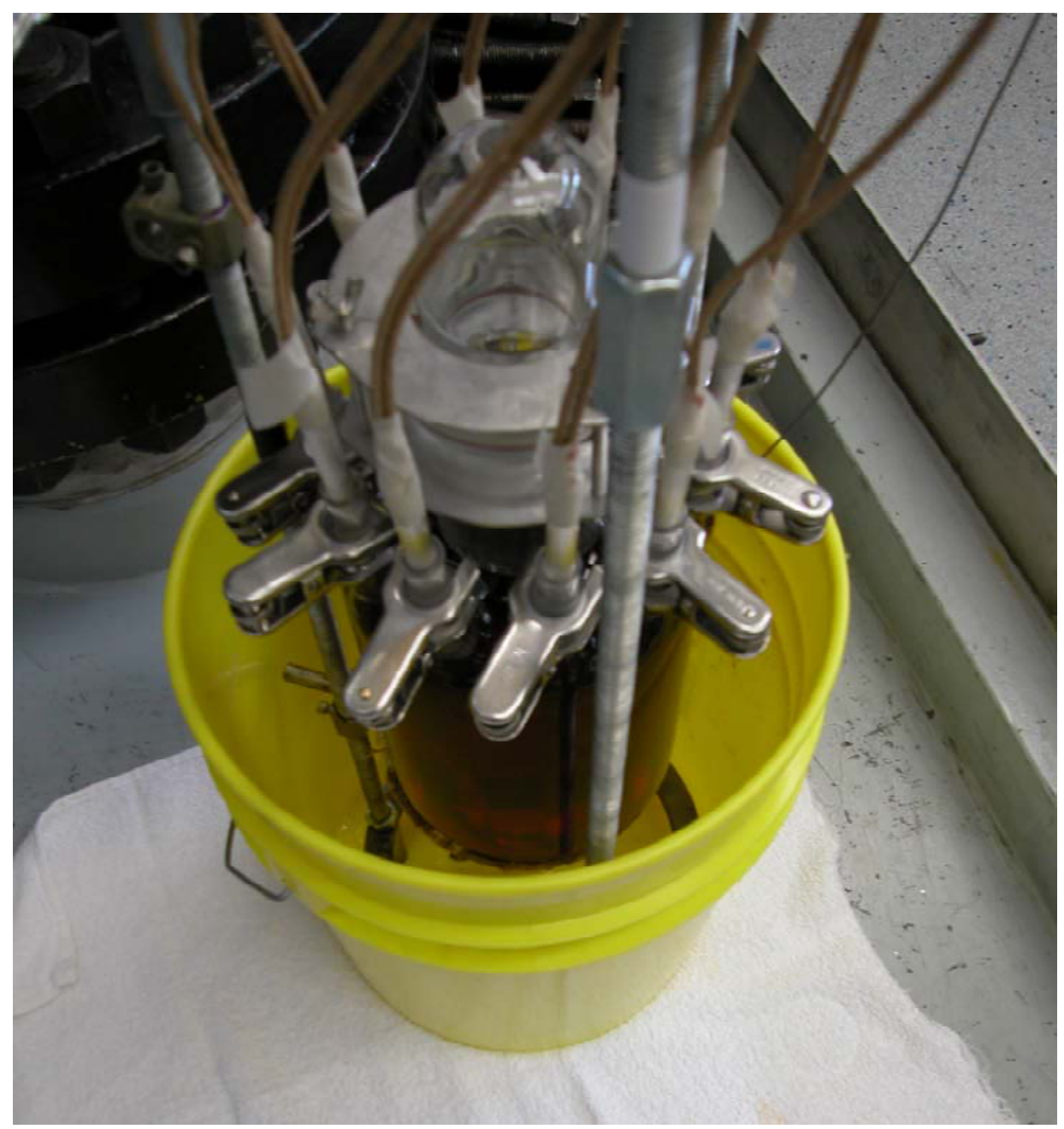

I think the picture looks better rotated, but your call.

Trials to date with chemicals show that reactive distillation remains a possible solution for HI decomposition. The configuration of the equipment in the initial chemical trials did not allow for the target temperature $\left(300^{\circ} \mathrm{C}\right)$ for $\mathrm{HI}$ decomposition. The highest temperature achieved thus far in the reaction zone of the glass column is $150^{\circ} \mathrm{C}$.

However, hydrogen was produced under these conditions at a production rate of one liter per hour. HI decomposition was achieved for the first time with the apparatus. Based on these results, modifications to the equipment have been completed to allow for sustaining the target temperature in the reaction zone of the glass column. 


\section{Remaining Tasks}

Trials are underway to determine the viability of the reactive distillation process. In a parallel effort, HI decomposition using extractive distillation is also being evaluated at GA. The methods and results will be compared and one process will be selected for integration with the bench-scale devices for the other two sections. Target date for this selection is 30 May 2005. Based on the production rates of hydrogen achieved, work in reactive distillation will continue in the design of a system based on engineered materials, or the effort in HI decomposition will shift solely to extractive distillation technology. 